\title{
Measurement and Analysis of International Air Parcel Shipping Environment for DHL and FedEx between Europe and United States
}

\author{
By Manuel-Alfredo Garcia-Romeu-Martinez,1* S. Paul Singh,2 \\ Vicente-Agustin Cloquell-Ballester 3 and Koushik Saha 2 \\ ${ }_{1}$ ITENE (Technological Institute of Packaging,Transportation and Logistics),Valencia, Spain \\ ${ }_{2}$ School of Packaging, Michigan State University, East Lansing, MI, USA \\ 3 Valencia University of Technology,Valencia, Spain
}

Various studies have been conducted to determine the dynamics that single packages undergo during distribution between destinations as a function of package size and weight and carrier. Previous studies have normally focused on regional and domestic measurements of these environments in Europe and North America. However, no information is available to determine the international handling and shipping environment of single parcels between the two continents. This study used instrumented packages containing triaxial accelerometers. The measured shocks were analysed to determine the velocity change levels as a function of the events measured in the distribution environment and to develop data for drop heights that can be used for package testing. This study provides a comparison of DHL and FedEx, the two largest international parcel carriers.

\section{INTRODUCTION}

In the last decade, there has been a growth in the shipment of individual packages between busi-ness-tobusiness (B2B) companies and from busi-nesses to consumers (B2C). These types of shipments are referred to as 'single-parcel ship-ments'. The parcel delivery industry is one of the fastest growing transportation and logistics sectors in both the North American and European economies. The parcel delivery industry makes a direct contribution to the gross domestic product of the European Union of over $€ 10.5$ trillion.1 Parcel carriers transport over $12 \%$ of the value of all goods, and this represents about $10 \%$ of the US gross domestic product. 2 It is therefore important to understand the physical movements that pack- aged goods undergo in this unique environment that can include multiple modes of transportation from the manufacturer to the consumer's door. The core business of the express industry is the provision of value-added, door-to-door transport deliveries of next-day or timedefinite shipments between 2 and 3 days, including documents, parcels and merchandise.

Today there are four major companies (DHL, FedEx, TNT and UPS) that are the leaders of the global express industry. However, there are many others that have regional presence in this highly competitive sector. These global delivery services are growing through mergers and alliances between private express companies, parcel and freight companies, and leading national post offices. The express industry simplifies and speeds the process of transporting goods. It organizes collection, usually at the end of the business day, allows the sender access to information on the progress of shipments from pick-up to delivery and provides proof of delivery. Where shipments cross international borders, the parcel express industry handles customs clearance as well as the payment of duties and taxes as required. Figure 
1 illustrates the key stages involved in a typical international express delivery or parcel shipment.

To meet the requirements of business between Europe and USA, the express industry relies on overnight transport to use the 'dead time' from when a company hands over its shipment late in the working day to delivery to the recipient early the following day. Express transportation should be achieved by using a variety of different transport modes: lorries, vans, trains, passenger aircraft and freight aircraft, as well as on-foot delivery. Where possible, though, the express industry uses surface transport modes. Air express services are only used where there are no other options available to meet same-day and next-day delivery requirements.

Since packaged goods are shipped using various means of transportation, there has been an increased effort over the past decades to measure and analyse the dynamic events that occur to pack ages in a given type of shipping environment. It is important for packaging engineers to design protective packaging while minimizing excess packaging based on environmental concerns. These contradictory and challenging factors, along with a low-cost overall requirement, have increased the demand for the 'just-right' or 'optimum' packaging so both underpackaging and overpackaging are avoided. In order to develop an optimum packaging, it is important that packaging engineers know the expected physical and climatic hazards that packages will encounter during shipping and handling. This information allows them to engineer the right amount of protective packaging needed. To help designers to reduce cost, either avoiding wasting packaging materials for overpackaging or avoiding damage from underpackaging, test methods to determine the dynamic levels of drops and impacts have been well established based on previous studies in the USA.3-6

Goff3 developed performance requirements that were necessary for US parcel postpackages in 1974. Singh and Voss4 measured the dynamics of small parcel environment in the domestic US ground-shipping environment for UPS. Singh and Cheema5 measured the domestics US next-day air environment for UPS and FedEx, and Singh and Hays6 measured the environment within UPS for packages of large size and weight in the USA. The 'second-day air' shipping environment was also measured in the USA for small, lightweight packages moving through FedEx.7 In a recent study, comparisons were done for the 'next-day air' shipping environment for mid-sized and lightweight packages moving through DHL, FedEx and UPS.8 However, no published data are available on midsized and lightweight packages for international parcel shipping environment between major global carriers like DHL and FedEx between Europe and the USA.

This study focused on measuring and analysing the international shipping environment for midsized $(0.36 \mathrm{~m} \times 0.34 \mathrm{~m} \times 0.34 \mathrm{~m})$ and lightweight $(6.5 \mathrm{~kg})$ packages shipped using FedEx and DHL between Europe and the USA. In addition, the results were used to provide recommended test levels for drop-testing packages of this size and weight for the international single-parcel shipping environment between Europe and the USA. These studies can be very expensive and timeconsuming because of international shipping costs and customs challenges to ship expensive datacollection recorders back and forth.

\section{EXPERIMENTAL DESIGN AND SETUP}

The data recorders used to collect dynamic data for this study were the 'Environmental Data Recorder- 3C' (EDR-3C) manufactured by Instrumented Sensor Technology (IST) (Michigan, USA) and are shown in Figure 2. The EDR-3 is a portable, digital sensor/recorder designed to measure shock in any impact orientation, vibration, temperature, humidity and pressure in packages during 
shipping. The positive slope pre-trigger and the negative slope post-trigger number of samples to be recorded were set at 30 and 150 samples, respectively. The sampling rate was $3200 \mathrm{~Hz}$ and the trigger level was $14 \mathrm{G}$ for all three axes (this trigger level guaranteed that minor shocks were ignored). The dead time after an event was set at $140 \mathrm{~ms}$. The test duration was set at 60 days and the recorder was set to fill-and-stop mode. The data were collected between Valencia, Spain in Europe and East Lansing, MI in the USA.

Test packages were used to ship the EDR-3C units. These were formed by encasing the EDR$3 \mathrm{~s}$ in high-density polyethylene foam cushions placed inside a two-piece, blow-moulded, doublewalled reusable plastic shipping case closed with four metal latches. This reusable shipping case was placed in a corrugated board box. The corrugated board box was sealed using a generalpurpose plastic box sealing tape. The test packages were $0.36 \mathrm{~m} \times 0.34 \mathrm{~m} \times 0.34 \mathrm{~m}$ (external dimensions) in size and weighed $6.5 \mathrm{~kg}$ (Figure 2).

The shipments for this study were conducted between April 2006 and June 2006. Twelve packages were shipped from East Lansing, MI, USA to Valencia, Spain. Six of them were shipped through FedEx and the other six through DHL. In addition to measuring the package dynamics, the effect of warning labels for safe handling was also studied. Half of the test packages shipped had the label (fragile, handle with care) placed on all four faces. The actual labelled packaged is shown in Figure 3.

The test packages were picked up from the School of Packaging at Michigan State University and loaded in a small delivery vehicle referred to as a 'package car'. The packages were taken to their respective carrier operating centers, where they were consolidated with other packages and scheduled for international express delivery. The consignment of the packages was placed into airtransport containers, which were then transported by truck to their respective national air hub in the USA. The air containers were unloaded and transferred on rollers to the central sorting area where employees removed the packages from the containers, scanned them and sent them on belts to a central sorting area where sophisticated scanners tracked and checked the packages' destination and size. As packages sped through the hub on a long network of belts and chutes, diverter arms activated and discharged packages down chutes and onto proper sort belts. The packages were then collected, grouped by destination and organized based on whether any special handling was required. Due to international shipment, the packages were sent to an export clearance process.

After sorting and pre-customs approval, the packages were consolidated with other packages bound for the same destination. They were then loaded into containers and onto a 'freighter' aircraft to be delivered to the respective air hub in Europe. The air containers were again unloaded and transferred on rollers to the central sorting area. After sorting again, the packages were consolidated with other packages bound for the same and onto another 'feeder' aircraft to be delivered to the respective air hub in Spain. After sorting and customs clearance, they were then loaded into containers and onto another 'feeder' aircraft or onto a truck to be delivered to the destination facility in Valencia. After sorting at the local operating facility, the packages were loaded into the 'package cars' to be delivered to the local destination.

A similar process was followed for return shipments from Valencia, Spain to East Lansing, MI, USA. The entire round trip took approximately 10-15 days, depending on the 
custom clearance process. The data from each EDR-3C for each shipment were uploaded into a computer, processed and then imported into a spreadsheet for further analysis and tabulation.

\section{DROP-HEIGHT MEASUREMENT}

There are two different approaches to calculate the drop height based on the data obtained from data recorders. The first is by using the free-fall time (real drop height, RDH), which measures the real heights packages are dropped from. The second is by using the parameters characteristics from the recorded shock pulse (effective drop height, EDH).

$\mathrm{RDH}=\frac{1}{2} \quad g \cdot \stackrel{2}{f} r \quad f$

$\mathrm{EDH}=\frac{2 \cdot}{2 g \cdot \quad)^{2}}$

where ' $g$ ' is the acceleration of earth's gravity, ' $t$ ' is the time measured for the free fall, ' $\Delta V$ ' is the velocity change of the pulse recorded and ' $e$ ' is the coefficient of restitution between the package and the impact surface.

One challenge with measuring drop height with $\mathrm{RDH}$ is that it gives the same value for height whether the package is dropped vertically or tossed sideways from the same height because the free-fall time is the same in either case. Also, most of the recorded events in real shipments are impacts, tosses and complex tumbles, which could be measurable, but do not have RDH. When the EDH is used, all the recorded events in real shipments are considered in the same way (free falls, tosses and complex tumbles). This is not ideal, since the shock duration and energy content of these kinds of events (free falls, tosses and complex tumbles) can vary and therefore have different effects on the package. Also, the coefficient of restitution ' $e$ ' between the package and the impact surface must be known. Consequently, the EDH was used to calculate or estimate the drop heights for this study, and a calibration was used to calculate the estimated coefficient of restitution based on the data from lab-based drop tests.

In order to compare the results with previous studies, 8 the same test package configuration and process of calibration were used. Packages were first calibrated to develop a 'package profile' based on 'e' values. These values were obtained by dropping the test packages from the same drop heights several times in each orientation (on the faces, at the edges and at the corners). A free-fall drop machine was used for the drops, and the internal recording device (EDR-3C) recorded each drop. After processing the data for drop height, the known drop height was provided to IST's DynaMax Suite software to create a 'package profile'.9 In these calibrations, it is assumed that the impact surface is a typical hard surface.

After receiving the packages back from an actual shipment, the 'package profile' created was then used to calculate and estimate the drop heights.

\section{DATA AND RESULTS}

Figure 4 illustrates one example of shock pulse recorded. For this particular shock, the drop height determined with the calibration 'package profile' provided for the manufacturer was $0.45 \mathrm{~m}$. Table 1 
summarizes the data for international shipments (USA-Spain and Spain-USA) for DHL and FedEx carriers with test packages with warning labels and without them. The results show that the highest estimated drop height was $1.24 \mathrm{~m}$. The drop heights are also listed for 90,95 and $99 \%$ occurrence levels. Adrop height of $0.98 \mathrm{~m}$ (FedEx, with warning label, 99\% occurrence) means that $99 \%$ of all drops were below this level. Also, the average number of drops in a one-way trip are listed. Figure 5 presents this information in a graphical form.

Table 2 presents the 10 maximum drop-height data in descending order. The results show that while the second, third and fourth drop heights decreased rapidly for FedEx and for DHL without warning labels, they did not decrease for DHL with warning labels. The maximum DHL drop height with warning label is between 43 and 49\% less than the FedEx and DHL without warning labels. This difference is about $60 \mathrm{~cm}$ with FedEx and $48 \mathrm{~cm}$ with DHL without warning labels. Table 1 shows that this trend with 5 and $10 \%$ of the drop heights disappeared, obtaining approximately the same drop height for both carriers and for both configurations. Table 2 shows that after the seventh highest drop, both carriers have approximately the same drop heights. This is also shown graphically in Figure 5.

The packages experienced a range of 17-66 drops above $76 \mathrm{~mm}$ in one-way-trip shipments using international express service between the USA and Europe. Table 3 shows the percentage of impacts resulting in drops onto the edges, faces and corners. This is also shown graphically in Figure 6. In true package free falls, the most likely impact orientations are edges and corners. Taking into account that a package has 6 faces, 12 edges and 8 corners, the probability of impacts on the faces is around $23 \%$, at the edges is around $46 \%$ and at the corners is around $31 \%$. The fact that face drops accounted in the study for $47 \%$ of all drops suggests that these drops were either controlled (guided) free falls resulting from handlers unloading top packages or from packages bouncing up and down during transportation.

\section{CONCLUSIONS}

The highest drop heights measured during shipments are one-time events that give a distorted picture of carrier performance. For the purpose of laboratory simulation of handling conditions, the $95 \%$ occurrence level is considered more appropriate. Based on the $95 \%$ data of older studies in the USA, 8 the international handling environments within DHL is $24 \%$ less severe than domestic USA handling environment, and the international handling environments within FedEx is $11 \%$ less severe than domestic USA shipping and handling environment (not significantly different among carriers). With the 95\% occurrence level, there is no significant difference between DHL and FedEx. There is also no significant difference between the use or absence of warning labels to handle packages with care or the presence of a fragile product. However, at $99 \%$ frequency of occurrence, both the type of carrier and the effect of warning labels are more apparent. Based on the data from Table 2, the effect of warning label based on the most severe drops, it is apparent that DHL shows a better handling with lower drop heights with warning labels as opposed to without them. This trend does not show in the shipments done by FedEx.

The data presented in this study assist users in the selection of drop heights for testing in orientations that are most likely to occur (based on the measured data in Table 3). The authors recommend using 95\% data levels. Based on this, a package will likely experience an average of 27 
drops in an international express parcel shipment, and 95\% of these drops will occur below a drop height of $0.57 \mathrm{~m}$.

\section{ACKNOWLEDGEMENTS}

The authors would like to thank the Consortium of Distribution Packaging Research (CDPR), Michigan State University, for providing the instrumentation and packaging used in this study. The study was a collaborative project funded by the CDPR and ITENE (Technological Institute of Packaging, Transportation and Logistics), Valencia, Spain.

We are grateful to engineers Jose Luis Argudo from ITENE and Pankaj Gaur from the School of Packaging, Michigan State University, the brokers in Valencia and Madrid, Vicente Rosalen Sancayetano from Pallas y Gadea and Asecomex, respectively, for all their valuable time and assistance to make this study possible across two continents and importation custom barriers.

\section{REFERENCES}

1. Oxford Economic Forecasting. The economic impact of express carriers in Europe. October 2004. http:// www.euroexpress.org/documents/uploads/kd0_ oef-en.pdf

2. Park M, Regan A. Issues in emerging home delivery operations. Research Paper, University of California Transportation Center, Los Angeles, CA, 2004.

3. Goff J. Development of performance standards for parcel post packages. Project $\mathrm{N}^{\circ} 3108$. Michigan State University, East Lansing, MI, 1974.

4. Singh SP, Voss T. Drop heights encountered in the United Parcel Service small parcel environment in the USA. Journal of Testing and Evaluation, American Society of Testing and Materials. 1992; 20(5): 382-387.

5. Singh SP, Cheema A. Measurement and analysis of the overnight small package shipping environment for Federal Express and United Parcel Service.
Journal of Testing and Evaluation, American Society of Testing and Materials. 1996; 24(4): 205-211.

6. Singh SP, Burgess G, Hays Z. Measurement and analysis of the UPS ground shipping environment for large and heavy packages. Journal of Testing and Evaluation, American Society of Testing and Materials. 2001; 29(1).

7. Singh SP, Burgess G, Singh J. Measurement and analysis of the second-day air small and lightweight package shipping environment within Federal Express. Packag. Technol. Sci. 2004; 17: 119-127. 8. Singh SP, Burgess G, Singh J, Kremmer M. Measurement and analysis of the net-day air shipping environment for mid-sized and lightweight packages for DHL, FedEx and United Parcel Service. Packag. Technol. Sci. 2006; 19: 227-235.

9. Lambert RJ. Package "e-factor" Profiling for Improved Equivalent Drop Height Measurement and Package Design. 2003; http://www.isthq.com23 


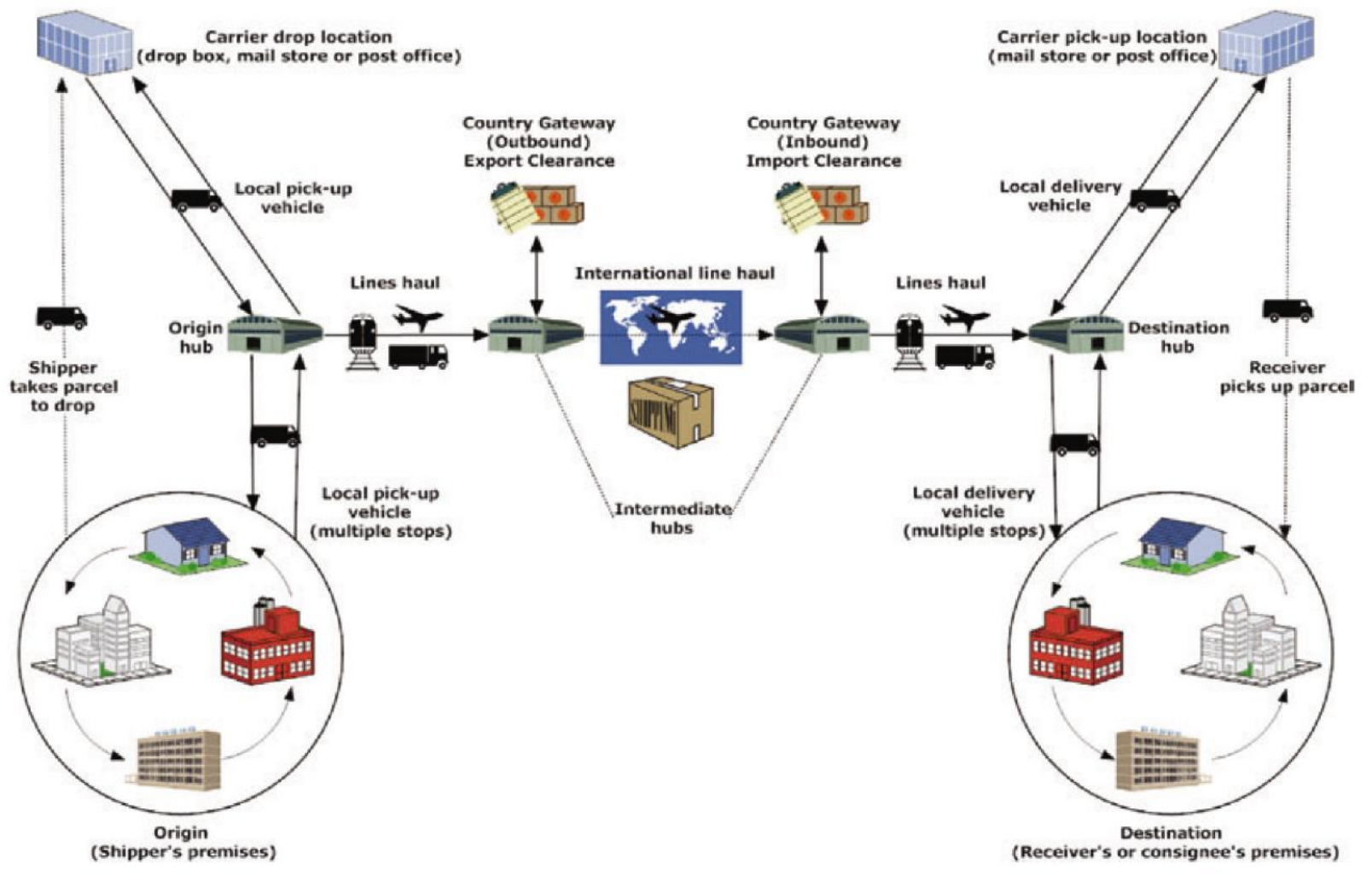

Figure I. Key stages of an international express parcel shipment.

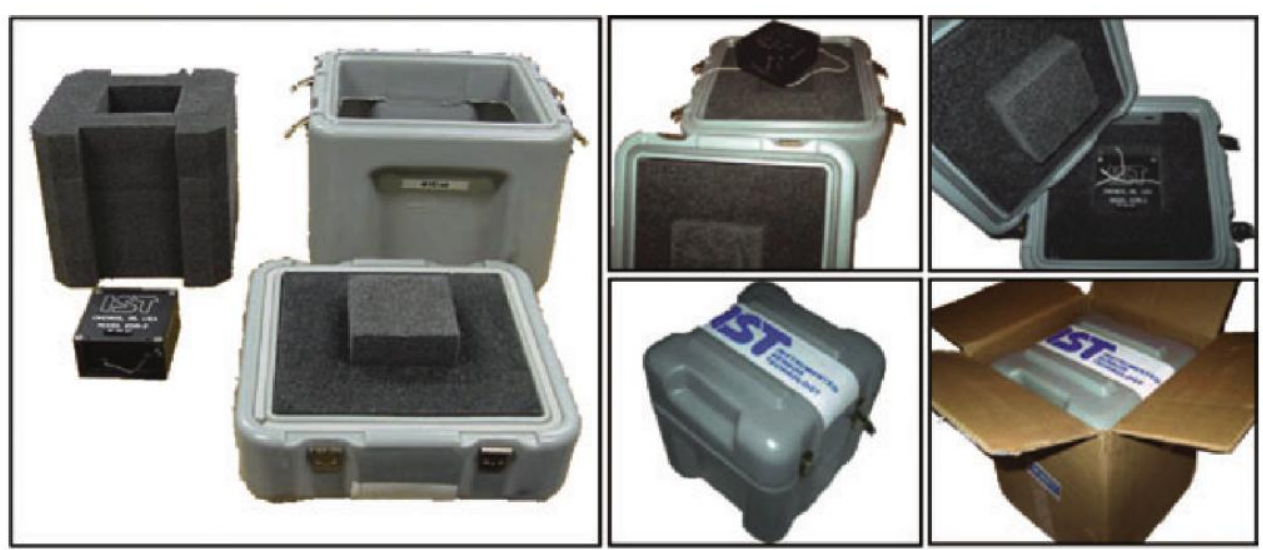

Figure 2. Preparation of the test packages. 

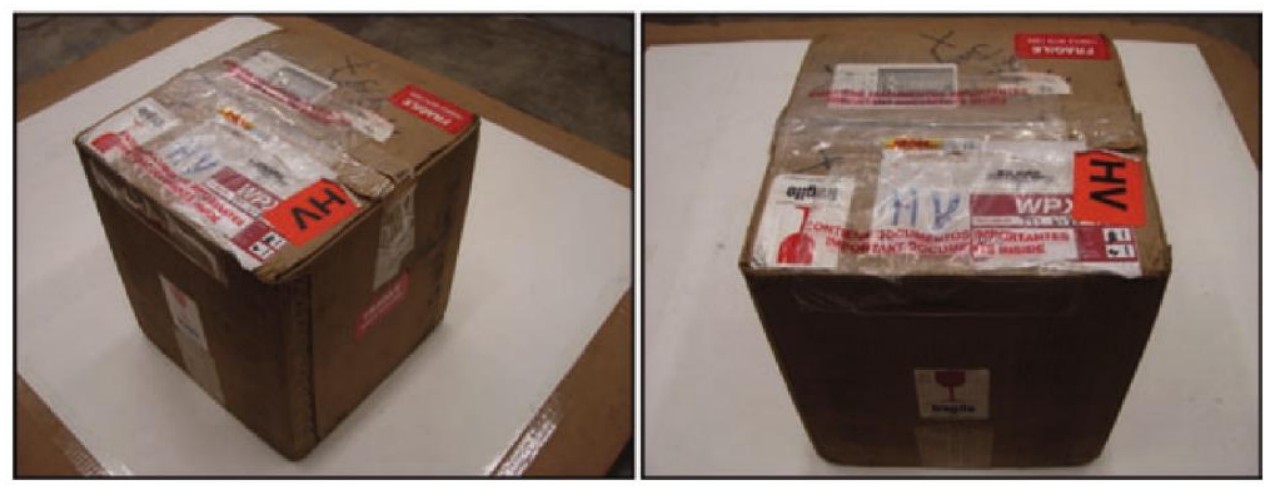

Figure 3. Packages with fragile, handle-with-care labels.

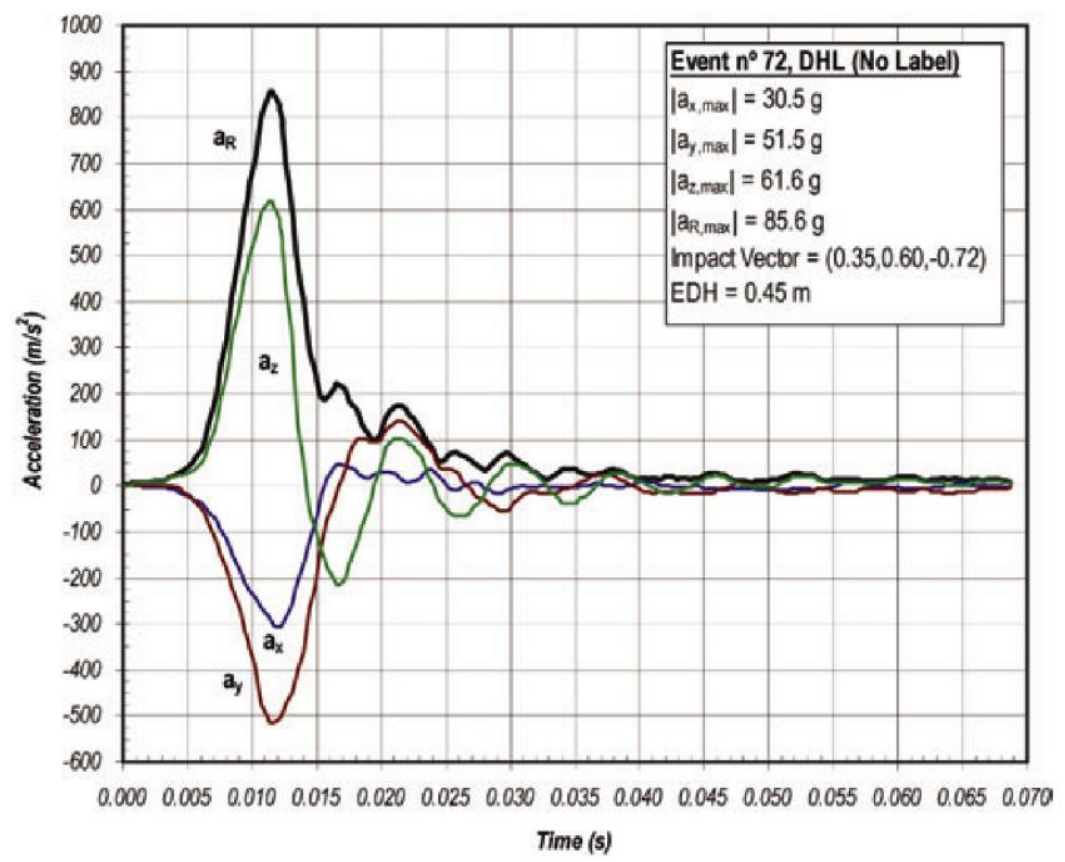

Figure 4. Example of shock pulse recorded.

Table I. Measured drop heights above $76 \mathrm{~mm}$

\begin{tabular}{|c|c|c|c|c|}
\hline \multirow[b]{2}{*}{ Drop data } & \multicolumn{2}{|c|}{ No label } & \multicolumn{2}{|c|}{ Label } \\
\hline & FedEx & $\mathrm{DHL}$ & FedEx & DHL \\
\hline $\begin{array}{l}\text { Average number of drops in a one-way trip } \\
\text { Maximum drop height }(\mathrm{m}) \\
\text { Drop height at } 99 \% \text { occurrence }(\mathrm{m}) \\
\text { Drop height at } 95 \% \text { occurrence }(\mathrm{m}) \\
\text { Drop height at } 90 \% \text { occurrence }(\mathrm{m}) \\
\text { Mean drop height }(\mathrm{m})\end{array}$ & $\begin{array}{l}21 \\
1.24 \\
1.06 \\
0.63 \\
0.39 \\
0.21\end{array}$ & $\begin{array}{l}36 \\
1.11 \\
0.89 \\
0.52 \\
0.38 \\
0.21\end{array}$ & $\begin{array}{l}24 \\
1.21 \\
0.98 \\
0.59 \\
0.37 \\
0.20\end{array}$ & $\begin{array}{r}29 \\
0.63 \\
0.58 \\
0.52 \\
0.42 \\
0.20\end{array}$ \\
\hline
\end{tabular}




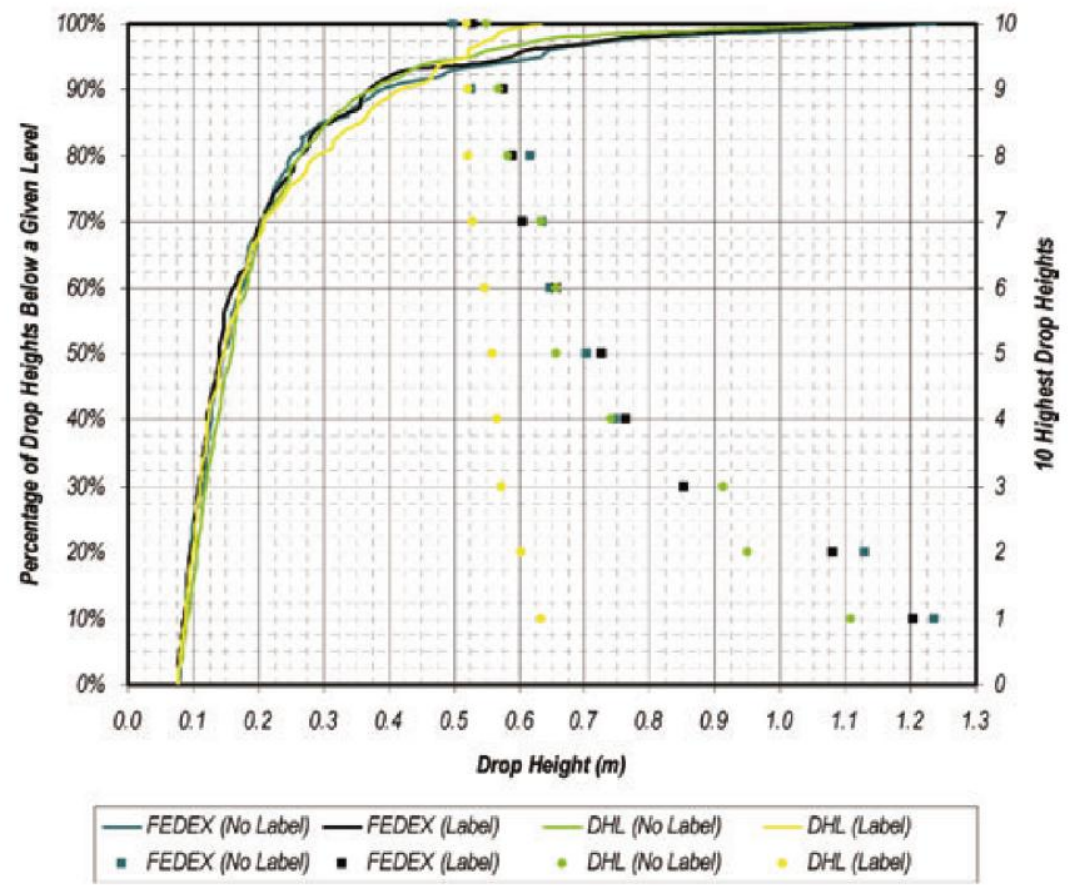

Figure 5. International air ex express delivery (percentage of drop heights below a given level).

\begin{tabular}{|lccccc|}
\hline \multicolumn{3}{|c}{ Table 2. Drop heights in descending order } \\
& \multicolumn{2}{c}{ No label } & & \multicolumn{2}{c|}{ Label } \\
\cline { 2 - 3 } \cline { 5 - 6 } Drop height $(\mathrm{m})$ & FedEx & $\mathrm{DHL}$ & & FedEx & $\mathrm{DHL}$ \\
\hline Highest & & & & \\
2nd highest & 1.24 & 1.11 & & 1.21 & 0.63 \\
3rd highest & 0.85 & 0.95 & & 1.08 & 0.60 \\
4th highest & 0.75 & 0.91 & & 0.85 & 0.57 \\
5th highest & 0.70 & 0.66 & & 0.76 & 0.57 \\
6th highest & 0.65 & 0.66 & & 0.66 & 0.56 \\
7th highest & 0.64 & 0.63 & & 0.61 & 0.55 \\
8th highest & 0.62 & 0.58 & & 0.59 & 0.52 \\
9th highest & 0.53 & 0.57 & & 0.58 & 0.52 \\
10th highest & 0.50 & 0.55 & 0.53 & 0.52 \\
& & & & \\
\hline
\end{tabular}

\begin{tabular}{|c|c|c|c|c|}
\hline \multicolumn{5}{|c|}{ Table 3. Impact orientation } \\
\hline \multirow[b]{2}{*}{ Orientation of drops (\%) } & \multicolumn{2}{|c|}{ No label } & \multicolumn{2}{|c|}{ Label } \\
\hline & FedEx & $\mathrm{DHL}$ & FedEx & $\mathrm{DHL}$ \\
\hline $\begin{array}{l}\text { Edge } \\
\text { Face } \\
\text { Corner }\end{array}$ & $\begin{array}{r}42.5 \\
53.5 \\
4.0\end{array}$ & $\begin{array}{l}45.8 \\
43.5 \\
10.7\end{array}$ & $\begin{array}{r}40.8 \\
50.3 \\
8.9\end{array}$ & $\begin{array}{l}46.1 \\
40.0 \\
13.9\end{array}$ \\
\hline
\end{tabular}




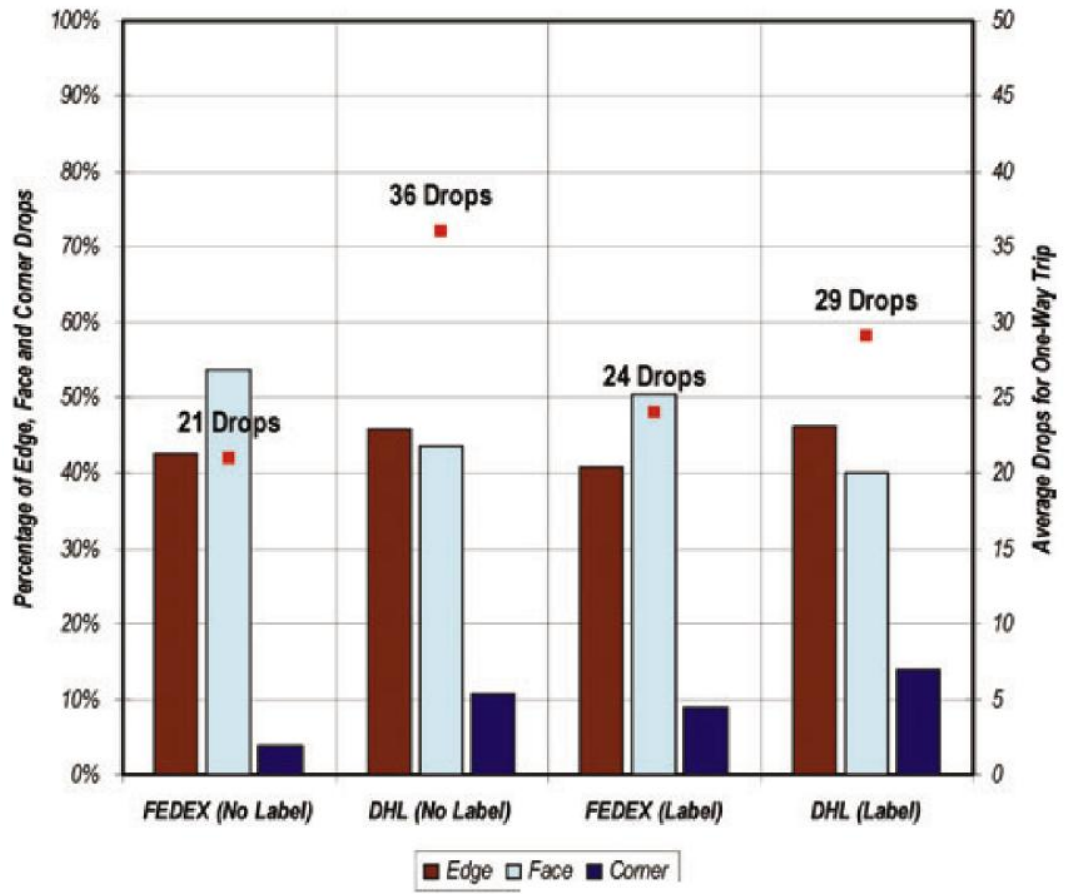

Figure 6. International air ex expre centage of edge, face and corr 